Accepted author's manuscript. Published in final edited form as:

Paediatrics \& Child Health 2020 (in press). Publisher DOI: 10.1093/pch/pxaa096

\title{
Extreme heat and paediatric emergency department visits in Southwestern Ontario
}

Authors: Piotr Wilk, PhD*1,2,3,4, Anna Gunz, MD, FRCPC, FAAP ${ }^{2,3,5}$, Alana Maltby, MSc ${ }^{1}$,

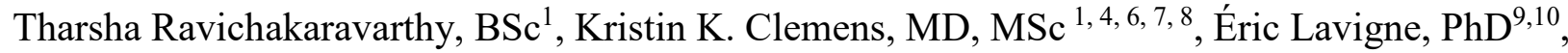
Rodrick Lim, MD, FRCPC $2,3,11$, Ana Maria Vicedo-Cabrera, $\mathrm{PhD}{ }^{12,13}$

\section{Affiliations:}

${ }^{1}$ Department of Epidemiology and Biostatistics, Western University, London, Ontario, Canada

${ }^{2}$ Department of Paediatrics, Western University, London, Ontario Canada

${ }^{3}$ Child Health Research Institute, London, Ontario, Canada

${ }^{4}$ Lawson Health Research Institute, London, Ontario, Canada

${ }^{5}$ Division of Paediatric Critical Care, Children's Hospital, London Health Sciences Center London, Ontario, Canada

${ }^{6}$ Department of Medicine, Western University, London, Ontario, Canada

${ }^{7}$ ICES, London, Ontario, Canada

${ }^{8}$ St. Joseph's Health Care, London, Ontario, Canada

${ }^{9}$ Air Health Science Division, Health Canada, Ottawa, Canada

${ }^{10}$ School of Epidemiology and Public Health, Faculty of Medicine, University of Ottawa, Ottawa, Canada

${ }^{11}$ Division of Paediatric Emergency Medicine, Children's Hospital, London Health Sciences Center, London, Ontario, Canada

${ }^{12}$ Institute of Social and Preventive Medicine, University of Bern, Bern, Switzerland

${ }^{13}$ Oeschger Center for Climate Change Research, University of Bern, Bern, Switzerland.

*Corresponding Author - Piotr Wilk 
Department of Epidemiology and Biostatistics, Schulich School of Medicine and Dentistry, Western University, Kresge Building, Room K201, 1151 Richmond Street, London, Ontario, N6A 5C1, Canada 


\begin{abstract}
Objective: The risk of adverse health events is expected to increase with hotter temperatures, particularly among the most vulnerable groups such as the elderly and children. The objective of this study is to assess the association between extreme heat and daily emergency department visits among children ( 0 to 17 years) in Southwestern Ontario.

Methods: We examined the average maximum temperature, relative humidity, and daily paediatric emergency department visits in June through August of 2002 to 2019. We reviewed emergency department visits from two academic hospitals. Daily meteorological data from one local weather station were obtained from Environment and Climate Change Canada. Conditional quasi-Poisson regression and distributed lag non-linear models were used to determine the association between daily maximum temperature and emergency department visits using relative risks and $95 \%$ confidence intervals.
\end{abstract}

Results: Extreme heat, observed at the $99^{\text {th }}$ percentile of the maximum temperature distribution, occurred at $33.1^{\circ} \mathrm{C}$ and was associated with an overall $22 \%$ increase in emergency department visits, compared to the reference temperature of $21^{\circ} \mathrm{C}$. This association was mostly found between the $2^{\text {nd }}$ and $5^{\text {th }}$ day after the exposure, suggesting a slightly delayed effect. The results of the sub-group analysis indicate that the risk of an emergency department visit due to infectious disease increases by $35 \%$ and the most pronounced association is in children aged 1 to 12 years. Conclusions: Extreme heat is associated with an increased incidence of emergency department visits in children. As temperatures continue to increase, strategies to mitigate heat-related health risks among children should be developed.

Key words: Heat, emergency department, child, health

\title{
Word Count: 2,114 words
}




\section{Introduction}

Climate change is anticipated to lead to increased temperature variability and temperature extremes, with negative effects on health (1-4). Temperature 'extremes' result from increasing average global ambient temperatures, an increase in the frequency and severity of heat waves, and increased pollution and exposure to ultraviolet radiation (5). Exteme heat events usually occur during a heat wave, a prolonged period of excessively hot weather relative to typical temperature in a particular location; on days with extreme heat, temperature significantly exceeds the average temperature for the whole period of heat wave (6). Existing evidence indicates that extreme heat adversely affects health $(7,8)$, particularly among the elderly $(8,9)$ and children $(5,10-12)$. Children, especially those less than five years old $(9,10,13)$, may be particularly vulnerable to the adverse effects of high temperatures $(13,14)$, due to their unique physiological, metabolic, and behavioral characteristics (15-17). High temperatures have been linked with infectious diseases in children including gastrointestinal diseases, hand, foot and mouth disease, and respiratory diseases (14). Furthermore, the incidence of renal disease, fever, and electrolyte imbalance increases significantly during heat waves (14). Extreme temperatures are associated with increased emergency department (ED) visits among children $(10,18,19)$. This increase has a lag of up to three days in infants, while toddlers and preschoolers are more likely to present to the ED on the day of the extreme temperature event (10).

Currently, there is limited evidence on how extreme heat can affect the health of children in Canada, including their use of ED services. Such evidence, however, is needed to monitor and understand national, provincial, and local across-time changes in the effects of extreme temperatures on paediatric health, as well as to inform local hospital and public health programs and policies that aim to mitigate adverse health effects. It is likely that ED preparedness and 
population-level prevention strategies aiming to address adverse environmental effects will produce more widespread and lasting improvements compared to individual prevention strategies (20). Thus, the objective of this study is to assess the association between extreme heat and daily ED visits among the paediatric population in Southwestern Ontario.

\section{Methods}

Setting. Southwestern Ontario covers 36,797 square kilometers and occupies most of the Ontario Peninsula, from the Bruce Peninsula in the north to Lake Erie in the south and from east to west, it stretches from Guelph to Windsor (21). In 2016, it had a total population of 2,583,544 (a population density of 70 per square kilometer) (21), with 383,822 residing in the City of London, the largest metropolitan area in the region (22).

ED visits. We reviewed the medical charts of paediatric ED visits (0 to 17 years) from Children's Hospital and University Hospital (both part of the London Health Sciences Centre), years 2002 through 2019. Children residing outside of Southwestern Ontario were excluded. Daily numbers of ED visits due to all causes excluding injuries (ICD 10: S00-T98) were derived for and stratified by age ( $<1$ year, $1-12$ years, and $13-17$ years); injuries (34.2\% of all ED visits during the study period) were excluded because their association with heat may not be explained by physiological mechanisms, but rather, by indirect mechanisms related to an increase in outdoor activities. Based on previous literature (e.g., Iniguez et al. 2016) (23) and biological plausibility, cause-specific daily ED visit counts were divided into two major groups of diseases, namely respiratory (ICD10: J00-J99) and infectious (ICD10: A00-B99) diseases.

Environmental data. Daily meteorological data from the weather station located at London International Airport (about $10 \mathrm{~km}$ from both hospitals) were obtained from Environment and Climate Change Canada (ECCC) for the period 2002 through 2019. We 
calculated daily maximum and average temperatures $\left({ }^{\circ} \mathrm{C}\right)$ and relative humidity $(\%)$ from hourly measurements. We obtained daily air quality health index (AQHI) data from ECCC, available for the period 2012 through 2019, which represents the relative risk of a mixture of common air pollutants (Ozone at ground level, Particulate Matter and Nitrogen Dioxide) known to have adverse effects on health. The AQHI is measured on a scale ranging from 1 to $10+$, with values grouped into health risk categories (1-3 low, 4-6 moderate, 7-10 high, and $10+$ very high) (24).

Data analysis. We measured the association between daily ED visits and daily maximum temperature with conditional quasi-Poisson regression and distributed lags non-linear models (DLNMs) $(25,26)$. As we were interested in measuring the association with heat, we restricted the study period to June through August. DLNM resembles the bi-directional time-stratified case-crossover design which controls for long-term and seasonal trends by matching case and control days within a year, month and day of the week. We modelled the non-linear and delayed association with daily maximum temperature though the so-called cross-basis function with a natural cubic spline function in the exposure-response dimension with internal knots at the $50^{\text {th }}$ and $95^{\text {th }}$ percentiles of the temperature distribution. Furthermore, a natural cubic spline with two internal knots placed in equally spaced values in the log scale was used for the lag dimension accounting for up to 7 days of lag. We controlled for national holidays with an indicator variable. Model choices were defined using quasi-Akaike Information Criterion. The analysis was repeated across two types of ED visits (respiratory and infectious diseases). We reported relative risks (RR) and $95 \%$ confidence intervals $(\mathrm{CI})$ at the $99^{\text {th }}$ percentile of the daily maximum temperature distribution, using the temperature at the minimum risk of ED visits as reference. Additional sensitivity analyses were performed to test the robustness of results. We first repeated the main analysis using daily average temperature as the main exposure, instead of daily 
maximum temperature. We then controlled for relative humidity in the model with a linear term of the moving average across the same day and day before, and, in a separate analysis, for the warmer period defined as May to September. Finally, using 2012-2019 data, we controlled for air quality levels using daily AQHI of the same day of exposure, also as a linear function. All analyses were completed in $\mathrm{R}$ version 3.6.2 (27).

Ethical and institutional approvals for the study were granted by the Western University Health Science Research Ethics Board and Lawson Health Research Institute.

\section{Results}

There were a total of 95,454 ED visits during the study period, an average of 57.6 per day. Children aged 1 to 12 years accounted for $63.5 \%$ of all visits (60,618 visits), followed by children aged 13 to 17 (20.9\%; 19,946 visits), and children below 1 year of age (15.6\%; 14,890 visits). ED visits due to infectious and respiratory diseases amounted for $13.5 \%$ and $16.6 \%$ of ED visits, respectively. Daily maximum and average temperatures ranged from 13.1 to $36.7^{\circ} \mathrm{C}$ and from 19.9 to $30.7^{\circ} \mathrm{C}$, with an average value for the whole period of $25.7^{\circ} \mathrm{C}$ and $20.1^{\circ} \mathrm{C}$, respectively. The daily AQHI ranged from 1.1 to 4.3 , with an average value of 2.3 .

Figure 1 (left panel) shows the overall cumulative association between maximum temperature and total ED visits (7 days of lag). Extreme heat, defined as the $99^{\text {th }}$ percentile of the daily maximum temperature distribution $\left(33.1^{\circ} \mathrm{C}\right)$ (vertical dashed line), was associated with a $22 \%$ increase in ED visits (RR of 1.22; 95\% CI: 1.12-1.32), compared to the reference temperature of $21.0^{\circ} \mathrm{C}$. Figure 1 (right panel) shows the distribution of the heat-ED visits association across 7 days after exposure. We observed that the association is mostly found between the $2^{\text {nd }}$ and $5^{\text {th }}$ day after exposure, suggesting a slightly delayed effect of heat on ED visits. 
Figure 2 shows the corresponding extreme heat-ED visits association estimates by disease group and by age. The overall risk of ED visits due to infectious disease increases by $35 \%$ (RR of $1.35 ; 95 \%$ CI: $1.07-1.72$ ) during the following 7 days after a heat day, while no evidence of association was found for respiratory diseases. For all ED visits, larger association estimates were found in children aged 1 to 12 years (RR of 1.33 ; 95\% CI: $1.20-1.47$ ) than in other age groups. A smaller and more imprecise association was estimated in older children (RR of $1.12 ; 95 \%$ CI: $0.94-1.32$ ) and the association was absent in the younger age group. Similar patterns across age categories were observed for the two disease groups. Only the children aged 1 to 12 years had an increased risk in ED visits due to infectious diseases (RR of $1.51 ; 95 \% \mathrm{CI}$ : 1.13-2.00). The results of the sensitivity analysis indicate that 1) using daily average temperature as the main exposure, 2) controlling for relative humidity, 3) using a longer study period, and 4) controlling for AQHI, did not substantially affect the relationship between heat and ED visits (see Table 1).

\section{Discussion}

In this study, we found that extreme heat was associated with a $22 \%$ increase in ED visits among children in Southwestern Ontario. This association was mostly found between the $2^{\text {nd }}$ and $5^{\text {th }}$ day after the exposure, which suggests a slightly delayed effect. Children between the ages of 1 and 12 experienced most of the ED visits (63.5\%). Moreover, the effects of extreme heat were most evident in this age group for all causes (excluding injury), as well as infectious diseases.

This is the first study to examine the relationship between extreme heat and paediatric ED use in the Canadian context, and the results parallel previous studies $(10,28)$. The observed lag effects of exposure for our population, assessed to up to a week post-exposure, are similar to results found for children in the United States, in Atlanta (5-18 years old) (28) and in New York 
City (NYC; $<4$ years old) (10). The number of very hot days in summer in the study region is expected to rise over the upcoming decades; in fact, the Climate Atlas of Canada predicts the number of very hot days $\left(>30^{\circ} \mathrm{C}\right)$ per year in the City of London, Ontario will increase from an average of 12 (1976 - 2005) to an average of 33 (2021 - 2050) (29). Hospitals should develop appropriate surge-capacity and emergency preparedness protocols and procedures.

Children of different ages appear to experience heat-related illnesses differently and this is demonstrated by variability in ED presentation rates between age groups, and potentially explains differences in the day peak lag-effect after exposure between age groups and across studies $(10,28)$. It is possible that behavioural modifications that alter heat exposure by age may modify the heat-illness association, as well as the different prevalence of infections and respiratory diseases by age. Unlike the association observed in the NYC paper (10), we did not see a significant association between extreme heat and ED visits for children $<1$ year old. These differences may be a result of our smaller sample size, the differences in geography, and/or other social factors not accounted for in our study.

Considerable attention has been given to the observed association of respiratory diseases, particularly asthma, and temperature $(28,30-32)$, which is affected by other factors such as humidity (31), air pollution, and aerocilized pollen (32). Other disease and illness processes may be related to temperature, but larger studies would be required to identify associations.

There are limitations to this study. This was an ecological study, and we did not assess the individual factors that might mitigate or amplify heat effects, such as household socioeconomic factors. Also, the small sample size may have affected the ability to detect associations in the $<1$ year and 13 to 17 age groups, as the daily ED visit rates for these groups are substantially lower than for the 1 to 12 age group. The low number of ED visits that could 
translate into model non-convergence or low statistical power did not allow us to consider other groups of diseases (e.g. cardiovascular). Finally, in the sensitivity analysis involving removal of the potential confounding effect of air quality (AQHI), meteorological data came from a single weather station located at London International Airport which could produce some degree of exposure misclassification or Berkson error bias that could affect the precision of the estimates (33), but not the direction or magnitude of the association between heat and ED visits. We also did not control for the effects of each of the single air pollutants that are part of the AQHI; however, regardless of the confounding mechanisms of each air pollutant, the bias derived from not accounting for them would have the same direction (i.e. the confounding effect of each single pollutant would not be outbalanced between each other).

Overall, this study provides insight on the consequences of extreme heat among the paediatric population. Further investigation at the regional and national level are important to better understand the true impact of heat on child health, improve monitoring and surveillance strategies, and target interventions that are most effective to mitigate health-related illness in children.

\section{Acknowledgments}

This research was supported by funding from the Canadian Institutes of Health Research (Operating Grant ID: 410547), and the Department of Paediatrics and the Children's Health Research Institute (Translational Research Grant Fund). 


\section{References}

1. O'Neill MS, Ebi KL. Temperature extremes and health: impacts of climate variability and change in the United States. J Occup Environ Med. 2009;51(1):13-25. Epub 2009/01/13. doi: 10.1097/JOM.0b013e318173e122. PubMed PMID: 19136869.

2. Smoyer-Tomic KE, Kuhn R, Hudson A. Heat Wave Hazards: An Overview of Heat Wave Impacts in Canada. Natural Hazards. 2003;28(2/3):465-86. doi:

10.1023/a:1022946528157.

3. Bayram H, Bauer AK, Abdalati W, Carlsten C, Pinkerton KE, Thurston GD, et al. Environment, global climate change, and cardiopulmonary health. American Journal of Respiratory and Critical Care Medicine. 2017;195(6):718-24. doi: 10.1164/rccm.2016040687PP.

4. Kovats RS, Hajat S. Heat stress and public health: a critical review. Annu Rev Public Health. 2008;29:41-55. Epub 2007/11/23. doi: 10.1146/annurev.publhealth.29.020907.090843. PubMed PMID: 18031221.

5. Smith CJ. Pediatric Thermoregulation: Considerations in the Face of Global Climate Change. Nutrients. 2019;11(9). Epub 2019/08/29. doi: 10.3390/nu11092010. PubMed PMID: 31454933.

6. Bush E, Lemmen DS, editors. Canada's Changing Climate Report. Ottawa, ON: Government of Canada; 2019.

7. Sheridan SC, Allen MJ. Changes in the Frequency and Intensity of Extreme Temperature Events and Human Health Concerns. Current Climate Change Reports. 2015;1(3):155-62. doi: 10.1007/s40641-015-0017-3. 
8. Berry P, Clarke K, Fleury MD, Parker S. Human Health. 2014. In: Canada in a Changing Climate: Sector Perspectives on Impacts and Adaptation [Internet]. Ottawa, ON: Government of Canada; [191-232].

9. Basu R. High ambient temperature and mortality: a review of epidemiologic studies from 2001 to 2008. Environ Health. 2009;8:40. Epub 2009/09/18. doi: 10.1186/1476-069X-8-40. PubMed PMID: 19758453; PubMed Central PMCID: PMCPMC2759912.

10. Sheffield PE, Herrera MT, Kinnee EJ, Clougherty JE. Not so little differences: variation in hot weather risk to young children in New York City. Public Health. 2018;161:119-26. Epub 2018/07/02. doi: 10.1016/j.puhe.2018.06.004. PubMed PMID: 29960726; PubMed Central PMCID: PMCPMC6633908.

11. Li M, Gu S, Bi P, Yang J, Liu Q. Heat waves and morbidity: current knowledge and further direction-a comprehensive literature review. Int J Environ Res Public Health. 2015;12(5):5256-83. Epub 2015/05/21. doi: 10.3390/ijerph120505256. PubMed PMID: 25993103; PubMed Central PMCID: PMCPMC4454966.

12. Lam LT. The association between climatic factors and childhood illnesses presented to hospital emergency among young children. Int J Environ Health Res. 2007;17(1):1-8. Epub 2007/03/17. doi: 10.1080/09603120601124264. PubMed PMID: 17365075.

13. Prüss-Ustün A, Wolf J, Corvalán C, Bo R, Neira M. Preventing disease through healthy environments: a global assessment of the burden of disease from environmental risks. Geneva, Switzerland: 2016.

14. Xu Z, Etzel RA, Su H, Huang C, Guo Y, Tong S. Impact of ambient temperature on children's health: a systematic review. Environ Res. 2012;117:120-31. Epub 2012/07/27. doi: 10.1016/j.envres.2012.07.002. PubMed PMID: 22831555. 
15. Xu Z, Sheffield PE, Hu W, Su H, Yu W, Qi X, et al. Climate change and children's health-A call for research on what works to protect children. International Journal of Environmental Research and Public Health. 2012;9(9):3298-316. doi: 10.3390/ijerph9093298. 16. Mangus CW, Canares TL. Heat-Related Illness in Children in an Era of Extreme Temperatures. Pediatr Rev. 2019;40(3):97-107. Epub 2019/03/03. doi: 10.1542/pir.2017-0322. PubMed PMID: 30824495.

17. Berry P, Paterson J, Buse C. Assessment of Vulnerability to the Health Impacts of Climate Change in Middlesex-London. Ottawa, ON: Report Prepared for the Middlesex-London Health Unit, 2014.

18. $\mathrm{Xu} \mathrm{Z,} \mathrm{Hu} \mathrm{W,} \mathrm{Su} \mathrm{H,} \mathrm{Turner} \mathrm{LR,} \mathrm{Ye} \mathrm{X,} \mathrm{Wang} \mathrm{J,} \mathrm{et} \mathrm{al.} \mathrm{Extreme} \mathrm{temperatures} \mathrm{and} \mathrm{paediatric}$ emergency department admissions. J Epidemiol Community Health. 2014;68(4):304-11. Epub 2013/11/26. doi: 10.1136/jech-2013-202725. PubMed PMID: 24272920.

19. Xu Z, Huang C, Hu W, Turner LR, Su H, Tong S. Extreme temperatures and emergency department admissions for childhood asthma in Brisbane, Australia. Occup Environ Med. 2013;70(10):730-5. Epub 2013/07/26. doi: 10.1136/oemed-2013-101538. PubMed PMID: 23884454.

20. Rideout K, Kosatsky T, Lee KK. What role for environmental public health practitioners in promoting healthy built environments? Can J Public Health. 2016;107(1). doi: 10.17269/cjph.107.5221.

21. Statistics Canada. Census Profile, 2016 Census 2020 [cited 2020 June 12]. Available from: https://www12.statcan.gc.ca/census-recensement/2016/dp-pd/prof/index.cfm?Lang=E.

22. Statistics Canada. Census Profile, 2016 Census-London, City [Census subdivision], Ontario and Middlesex, County [Census division], Ontario 2019 [cited 2020 February 12]. 
Available from: https://www12.statcan.gc.ca/census-recensement/2016/dp-

pd/prof/details/page.cfm?Lang $=E \& G e o 1=C S D \& C o d e 1=3539036 \& G e 02=C D \&$ Code $2=3539 \& S$

earchText $=$ London $\&$ SearchType $=$ Begins $\&$ Search $P R=01 \& B 1=A 11 \& T A B I D=1 \&$ type $=0$.

23. Iniguez C, Schifano P, Asta F, Michelozzi P, Vicedo-Cabrera A, Ballester F.

Temperature in summer and children's hospitalizations in two Mediterranean cities. Environ Res.

2016;150:236-44. Epub 2016/06/19. doi: 10.1016/j.envres.2016.06.007. PubMed PMID:

27318256.

24. Government of Canada. About the Air Quality Health Index 2019 [cited 2020 February

27]. Available from: https://www.canada.ca/en/environment-climate-change/services/air-qualityhealth-index/about.html.

25. Armstrong BG, Gasparrini A, Tobias A. Conditional Poisson models: a flexible alternative to conditional logistic case cross-over analysis. BMC Med Res Methodol. 2014;14:122. Epub 2014/11/25. doi: 10.1186/1471-2288-14-122. PubMed PMID: 25417555;

PubMed Central PMCID: PMCPMC4280686.

26. Gasparrini A, Armstrong B, Kenward MG. Distributed lag non-linear models. Stat Med. 2010;29(21):2224-34. Epub 2010/09/03. doi: 10.1002/sim.3940. PubMed PMID: 20812303; PubMed Central PMCID: PMCPMC2998707.

27. R Core Team. R: A Language and Environment for Statistical Computing. Vienna, Austria: R Foundation for Statistical Computing; 2019.

28. O'Lenick CR, Winquist A, Chang HH, Kramer MR, Mulholland JA, Grundstein A, et al. Evaluation of individual and area-level factors as modifiers of the association between warmseason temperature and pediatric asthma morbidity in Atlanta, GA. Environ Res. 2017;156:132- 
44. Epub 2017/03/28. doi: 10.1016/j.envres.2017.03.021. PubMed PMID: 28342349; PubMed Central PMCID: PMCPMC5633283.

29. Prairie Climate Centre. Climate Atlas of Canada (version 2) - Municipality of London 2019 [updated July 10, 2019; cited 2020 March 3]. Available from:

https://climateatlas.ca/data/city/452/plus30_2030_85/line.

30. Kadhim Yousif M, Al Muhyi AA. Impact of weather conditions on childhood admission for wheezy chest and bronchial asthma. Med J Islam Repub Iran. 2019;33:89. Epub 2019/11/07. doi: 10.34171/mjiri.33.89. PubMed PMID: 31696083; PubMed Central PMCID: PMCPMC6825404.

31. Priftis KN, Paliatsos AG, Panagiotopoulou-Gartagani P, Tapratzi-Potamianou P, Zachariadi-Xypolita A, Nicolaidou P, et al. Association of weather conditions with childhood admissions for wheezy bronchitis or asthma in Athens. Respiration. 2006;73(6):783-90. Epub 2006/06/10. doi: 10.1159/000093817. PubMed PMID: 16763383.

32. D'Amato G, Pawankar R, Vitale C, Lanza M, Molino A, Stanziola A, et al. Climate Change and Air Pollution: Effects on Respiratory Allergy. Allergy Asthma Immunol Res. 2016;8(5):391-5. Epub 2016/06/24. doi: 10.4168/aair.2016.8.5.391. PubMed PMID: 27334776; PubMed Central PMCID: PMCPMC4921692.

33. Armstrong BG. Effect of measurement error on epidemiological studies of environmental and occupational exposures. Occup Environ Med. 1998;55(10):651-6. Epub 1999/02/04. doi: 10.1136/oem.55.10.651. PubMed PMID: 9930084; PubMed Central PMCID: PMCPMC1757516. 
Table 1. Extreme heat-related emergency department visit (all-cause, excluding injuries) association estimates expressed as relative risk and $95 \%$ confidence interval at the $99^{\text {th }}$ percentile of the maximum daily temperatures $\left(33.1^{\circ} \mathrm{C}\right)$ versus the temperature of minimum risk of emergency department visits.

\begin{tabular}{|l|c|}
\hline Type of Analysis & Heat RR (95\% CI) \\
\hline Main analysis (daily maximum temperature) & $1.22(1.12 ; 1.32)$ \\
\hline Sensitivity analysis: & \\
\hline 1) Using daily average temperature & $1.17(1.07 ; 1.28)$ \\
\hline 2) Controlling for relative humidity & $1.22(1.12 ; 1.32)$ \\
\hline 3) Warm period defined as May-September & $1.15(1.07 ; 1.25)$ \\
\hline 4a) Limiting study period to 2012-2019* & $1.17(0.96 ; 1.42)$ \\
\hline 4b) Controlling for daily AQHI* & $1.13(0.92 ; 1.37)$ \\
\hline
\end{tabular}

Note: air quality health index (AQHI); confidence interval (CI); relative risk (RR)

* Sensitivity analysis $4 \mathrm{a}$ and $4 \mathrm{~b}$ reported for the period 2012-2019 when daily air quality health index (AQHI) data were available. 
Table S1. Extreme heat-related emergency department visit association by groups of causes and age categories. Relative risk and 95\% confidence interval at the 99th percentile of the maximum daily temperatures $\left(33.1^{\circ} \mathrm{C}\right)$ versus the temperature of minimum risk of emergency department visits.

\begin{tabular}{|l|c|}
\hline Group of Causes and Age Category & Heat RR (95\% CI) \\
\hline All-cause (excluding injuries) - total & $1.22(1.12 ; 1.32)$ \\
\hline$<1$ year & $0.97(0.80 ; 1.19)$ \\
\hline $1-12$ years & $1.33(1.20 ; 1.47)$ \\
\hline $13-17$ years & $1.12(0.94 ; 1.32)$ \\
\hline Infectious - total & $1.36(1.07 ; 1.72)$ \\
\hline$<1$ year & $0.97(0.58 ; 1.62)$ \\
\hline $1-12$ years & $1.51(1.14 ; 2.00)$ \\
\hline $13-17$ years & $1.31(0.67 ; 2.58)$ \\
\hline Respiratory - total & $1.07(0.86 ; 1.34)$ \\
\hline$<1$ year & $0.88(0.54 ; 1.43)$ \\
\hline $1-12$ years & $1.20(0.93 ; 1.55)$ \\
\hline $13-17$ years & $0.68(0.38 ; 1.23)$ \\
\hline
\end{tabular}

Note: confidence interval (CI); relative risk (RR) 